\title{
Simple and rapid dipstick test for detection of dexamethasone adulteration in traditional herbal medicines
}

Bambang Kuswandi*,

Arimbi S Kartika,

Nia Kristiningrum,

Dwi K Pratoko,

Indah P Sary

Chemo and Biosensors Group, Faculty of Pharmacy, University of Jember, Jember, Indonesia Jl. Kalimantan 37, Jember, 68121, Indonesia

*Corresponding author:

Bambang Kuswandi

b_kuswandi.farmasi@unej.ac.id

\section{KEYWORDS:}

Dipstick test; Colorimetric method; Dexamethasone; Traditional herbal medicine; Jamu. https://www.pharmacy.mahidol.ac.th/journal/ (C) Faculty of Pharmacy, Mahidol University (Thailand) 2021

\begin{abstract}
Simple, rapid, and low-cost dipstick test has been fabricated for the detection of dexamethasone adulteration in traditional herbal medicine (Jamu) for the joint-pain killer. The dipstick test has been constructed by immobilization of $\mathrm{FeCl}_{3}$ and $\mathrm{K}_{3}\left[\mathrm{Fe}(\mathrm{CN})_{6}\right]$ in cellulose acetate film as a sensing film toward dexamethasone. The sensing film changes its color from green to blue in the presence of dexamethasone. It has response time at $10 \mathrm{mins}$ and good linearity in the range $0.5-75 \mu \mathrm{g} / \mathrm{ml}$ of dexamethasone with correlation coefficient (r) of 0.9997 , with the detection limit, was $0.422 \mu \mathrm{g} / \mathrm{ml}$. The dipstick tests have been successfully used for the detection of dexamethasone adulteration in jamu for the joint-pain killer, and the result demonstrated in good correlation with the UV spectrophotometry method. Thus, the dipstick test is simple, rapid, and low-cost; it can be used as an alternative method for the detection of dexamethasone adulteration in traditional herbal medicine.
\end{abstract}

\section{INTRODUCTION}

Traditional herbal medicines are commonly used in Indonesia and other Southeast Asian countries, such as Malaysia, Singapore, Thailand, Philippines, etc. for the treatment of various illness, The popularity of traditional herbal medicine called Jamu in Indonesia can be attributed to its long-time use, availability, simplicity, and relative inexpensiveness compared to conventional synthetic medicines jamu is still very popular in rural as well as in urban areas ${ }^{1}$. Based on its traditional use jamu is being developed into a rational form of therapy, by herbal practitioners and in the form of phytopharmaceuticals. Jamu has acquired a potential benefit, both economically and clinically. We surveyed the most frequently used plants in jamu that have also been investigated regarding their constituents and pharmacological effects. The Indonesian government has divided the preparation of medicinal plants into three categories, i.e. jamu, standardized herbal medicines and fitofarmaka (phytomedicines ${ }^{2}$ ). For example in Indonesia, jamu has been used for generations and linked to the cultural and traditional practices of most Indonesian people who therefore perceive the practice as their heritage and consider it as their local wisdom ${ }^{2}$. In this case, there is a common 
perception among consumers since traditional herbal medicines are natural, therefore they are safe, harmless, and free from adverse side effects. Like other herbal medicine, jamu can also induce serious adverse side effects, such as phototoxic reactions, contact urticaria, allergic contact dermatitis, angioedema, and anaphylaxis ${ }^{3,4}$.

These serious adverse side effects could be increased by many cases of contaminations or adulteration of herbal medicines with chemical synthetic drugs, e.g. corticosteroids ${ }^{5}$. In this case, herbal medicine formulations intended for antiinflammatory, anti-asthmatic effect, anti-allergic, etc. are most likely to be adultered with corticosteroids for faster action and affection ${ }^{6}$. Adulteration of herbal drugs with synthetic adulterants can lead to many complications including herb-drug interactions. Dexamethasone is one of the most frequently used adulterants in herbal formulation ${ }^{7}$ the antibiotic Polymyxin B (PLX) because it gives immediate relief from allergic symptoms due to suppression of the immune system. Therefore, dexamethasone is the most used adulterant of jamu for the jointpain killer in Indonesia ${ }^{5}$. Moreover, dexamethasone being the cheapest of the corticosteroids, so that it is commonly used to adulterate herbal medicine preparations ${ }^{6}$.

Commonly the adulterated dexamethasone in traditional herbal medicine is determined using chromatographic methods. Several works have been reported the use of chromatographic methods for the determination of the adulterated dexamethasone in traditional herbal medicine, such as HPLC ${ }^{8}$, UHPLC-Q-Orbitrap HRMS ${ }^{9}$, and LC-MS/MS ${ }^{10}$. However, these chromatographic methods are timeconsuming, destructive, expensive, need skilled personnel, and involving long procedure as well as used many toxic reagents ${ }^{4}$. Therefore, there is a need for a simple and rapid method as well as user-friendly for detection of dexamethasone adulteration in jamu as an alternative analytical method.

In this context, the objective of this work is to develop a simple and rapid method for the detection of dexamethasone adulteration in jamu, especially for the joint-pain killer. The dipstick test has been constructed by immobilization of $\mathrm{FeCl}_{3}$ and $\mathrm{K}_{3}\left[\mathrm{Fe}(\mathrm{CN})_{6}\right]^{11}$ onto cellulose acetate film in acid condition as the sensitive reagents toward dexamethasone. The dipstick test results toward dexamethasone presence in jamu were compared with the UV spectrophotometry method for validation purposes. The results were used to prove that the dipstick test can be used as an alternative method for simple and rapid detection of dexamethasone adulteration in traditional herbal medicine (jamu).

\section{MATERIALS AND METHODS}

\subsection{Dipstick test preparation}

The cellulose acetate was prepared from a used film in photography (Fuji film, Japan) and it was activated by increasing the film porosity and de-esterification of the acetyl groups in the film. It was carried out by hydrolyzing the film, using a $0.20 \mathrm{M} \mathrm{KOH}$ solution, and treating the film for $24 \mathrm{~h}$. Afterword, the film was rinsed with double distilled water, then the film immersed in $0.5 \%(\mathrm{w} / \mathrm{v})$ polyvinyl alcohol solution (PVA), and it was found good enough for activation of the film ${ }^{12}$.

The sensitive reagent for dexamethasone was prepared by mixed $\mathrm{FeCl}_{3}(10 \% \mathrm{w} / \mathrm{v}, 20 \mathrm{~mL})$ and $\mathrm{K}_{3}\left[\mathrm{Fe}(\mathrm{CN})_{6}\right.$ solution $(10 \% \mathrm{w} / \mathrm{v}, 5 \mathrm{~mL})$ and then added with sulphuric acid (2M, $20 \mathrm{ml})$ equally as recommended elsewhere ${ }^{11}$. Afterward, the mixture was stirred until the green color product appears. The reagent solution was stored in a dark container and stored in a chiller condition for further use.

To immobilize the reagents on the film $(10 \mathrm{~mm} \times 5 \mathrm{~mm})$ as a sensing area as shown in Fig. 1(a), it was treated with the reagents at an optimized concentration at room temperature $\left(\sim 25^{\circ} \mathrm{C}\right)$ for $24 \mathrm{~h}$. Then, the film was dried, and afterword it was attached to the stick (white plastic sheet) using double tape. Finally, the dipstick test constructed was placed in sealed aluminum foil and stored in a chiller condition for further use.

\subsection{Sample preparation}

Jamu samples for the joint-paint killer that did not have official registration from the food and drug administration, Republic of Indonesia (BPOM) were used as suspected real samples and purchased from the local jamu shop in Jember. A 1 gram of powdered jamu, was extracted with $10 \mathrm{~mL}$ of methanol in water (methanol: water 1:2 $\mathrm{v} / \mathrm{v}) .{ }^{13}$ Afterword, the mixture was stored in a water-bath, shook, and heated at $70 \pm 2^{\circ} \mathrm{C}$ for $15 \mathrm{mins}$ 
using a shaker. The mixture was filtered through a filter paper (Whatman No. 41), and the filtrate was collected for further detection. While for UV spectrophotometry method ${ }^{13}$, then each filtrate of sample solution was filtered using PTFE filter $(0.45 \mu \mathrm{m})$, to avoid any suspended particle that may present in a sample.

\subsection{Dexamethasone detection}

In general, standard dexamethasone solution or sample solution is taken by pipetted $(3 \mathrm{~mL})$ and transferred onto a small container, then the dipstick test was immersed. Afterward, a flatbed scanner (CanoScan, LIDE 110, Japan) is employed to capture the color change with 300 dpi resolution using a color photo mode. Then the scanned color intensity (JPEG format) was calculated using the ImageJ program to generate the average value of the blue color. Here, the mean blue was selected as the response, since its color change from green to blue. For quantitative measurement, each mean blue value of standard dexamethasone solution or sample addition was subtracted with that of blank and presented as $\Delta$ mean blue. Hence, dexamethasone concentration in the sample was calculated using the calibration curve constructed from standard dexamethasone solution. All of the measurements were performed in triplicate.

To validate the developed dipstick method toward dexamethasone detection, It has been performed by measuring the precision and accuracy of dexamethasone detection in simulated jamu samples. Furthermore, the results of the dipstick method in the detection of dexamethasone in real samples were also validated using the UV spectroscopy as a reference method.

The dexamethasone detection by UV spectrophotometric was performed based on the suggested method elsewhere ${ }^{13}$. Briefly, $100.0 \mathrm{mg}$ dexamethasone were transferred to volumetric flasks $(25 \mathrm{~mL})$ and added with $15 \mathrm{~mL}$ of diluted methanol (methanol: water 1:2 v/v). Then they were ultrasonicated around $15 \mathrm{~min}$ and diluted with diluted methanol to the volume of flask. Afterword, the solutions were filtered via filter paper (Whatman No. 41). The double-distilled water was used to dilute the subsamples of the solutions to obtain $1000 \mu \mathrm{g} / \mathrm{ml}$. as the final concentrations as a stock solution. A UV (Hitachi
U2000®UV/VIS spectrophotometer, Japan) spectroscopic scanning was performed between 200-400 nm with the blank solution to choose the maximum UV wavelength ( $\lambda$ max). Usually, around $241 \mathrm{~nm}$ was found for $\lambda \max$ for dexamethasone detection in an aqueous solution. To distinguish the signal derived from dexamethasone and other component's signal in the jamu extract, it has been performed by analyzing solutions containing all the components of the dexamethasone in jamu, except the jamu without dexamethasone (placebo). The system response was examined for the presence of interference that may present in jamu or overlaps with dexamethasone responses at $241 \mathrm{~nm}$. Furthermore, the UV spectrometer as the reference technique was also validated for analysis dexamethasone in plant-derived samples as the precision and accuracy of dexamethasone analysis, while its linearity was validated using as the software of Validation Method of Analysis. The measurements were done using double distilled water as blank. All of the experiments were carried out in triplicate. The results of dexamethasone concentration in jamu samples detected by the dipstick test were compared with the UV spectrophotometry using the t-test ${ }^{14}$, and the correlation between both methods was performed using analysis of correlation ${ }^{14}$.

\section{RESULTS AND DISCUSSION}

The dipstick test for dexamethasone detection is based on oxidized dexamethasone by $\mathrm{FeCl}_{3}$ in the acidic condition and create $\mathrm{Fe}$ (II). Then, $\mathrm{Fe}$ (II) ion reacts with $\mathrm{K}_{3}\left[\mathrm{Fe}(\mathrm{CN})_{6}\right]$ (potassium hexacyanoferrate (III)) and produces bluish-green iron (II) ferricyanide complex $\left(\mathrm{KFe}\left[\mathrm{Fe}(\mathrm{CN})_{6}\right]\right) .{ }^{11}$ The mechanism involved in the reaction of dexamethasone is two-electron oxidation of ketol side chain using Fe (III) as an oxidizing agent, where the dipstick test color change toward dexamethasone solution $(10 \mu \mathrm{g} / \mathrm{ml})$ from green to blue (Fig. 1(b)).

The effect of $\mathrm{FeCl}_{3}$ and potassium $\mathrm{K}_{3}\left[\mathrm{Fe}(\mathrm{CN})_{6}\right]$ as the sensitive reagents on the dipstick test response ( $\Delta$ mean blue) were optimized toward $5 \mu \mathrm{g} / \mathrm{ml}$ dexamethasone. The reagent optimization was performed at the mixed reagent solutions at the concentration of $0.5 \% ; 1.0 \% ; 5.0 \%$ and $10 \%$. Afterword, the sensitive films were attached to the dipstick test and tested with dexamethasone ( $5 \mu \mathrm{g} / \mathrm{ml})$. The color change was captured using ImageJ to measure $\Delta$ mean blue value (Fig. 1(c)) 
for each reagent concentration used. It was found that the concentration of the reagent at $10 \%$ was shown to give distinguish visual color change compared to other concentrations. The $10 \%(\mathrm{w} / \mathrm{v})$ reagent concentration was used as an optimum concentration. The color reaction was performed at room temperature, however at high temperature $\left(70^{\circ} \mathrm{C}\right)$ the developed color occurred more rapidly as also found in many chemical reactions that affected by temperature ${ }^{11}$. However, the room or ambient temperature was used for the simplicity of measurements.

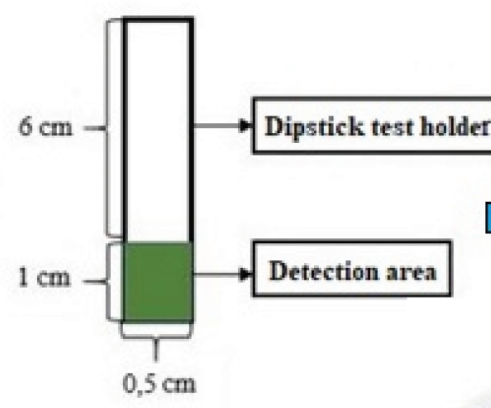

(a)

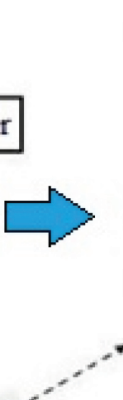

(b)

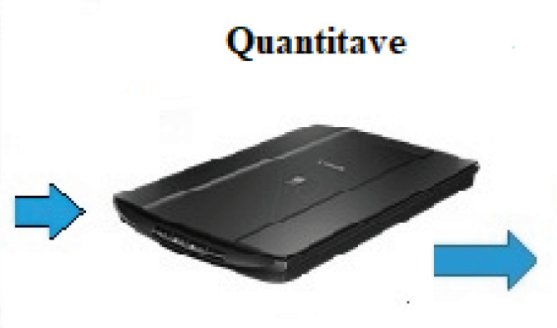

(c)
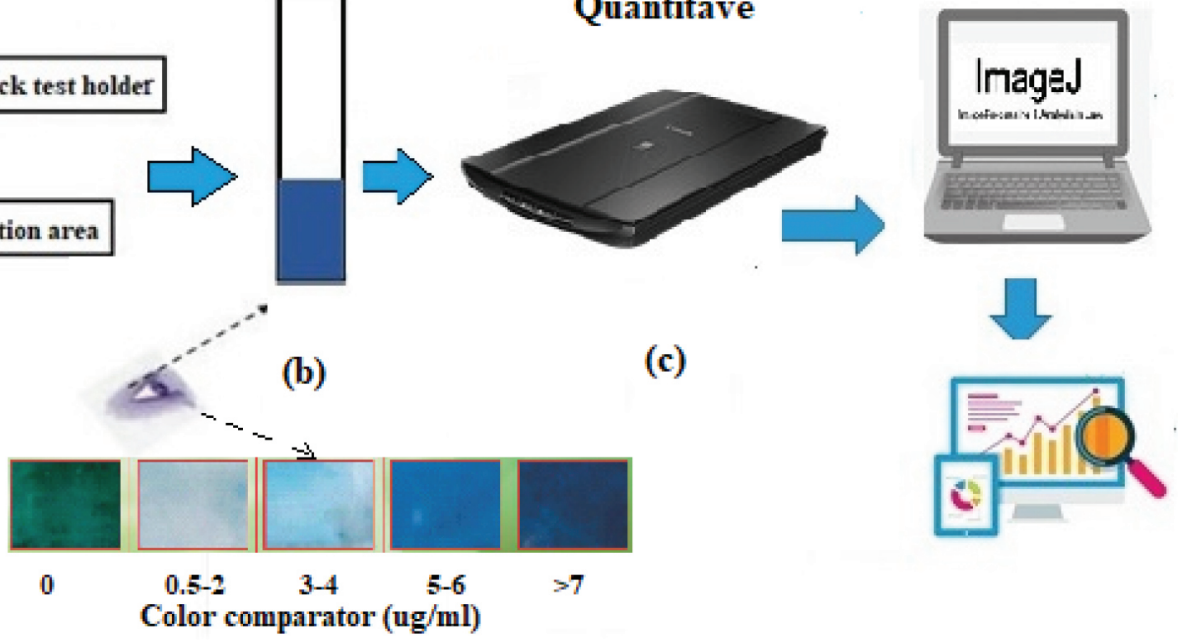

\section{Semiquantitative}

\section{(d)}

Figure 1. The dipstick test design (a) and the color change after reaction with dexamethasone (b) and type of measurements for quantitative (c ) and semiquantitative (d)

The optimization of the reagents immobilization time has been performed by varying the time for immersing the film into the reagent solution. The time variation was within $30 \mathrm{hrs}$ of observation. The sensitive film that has been impregnated with the reagent solution, then attached to the dipstick test and reacted toward dexamethasone solution ( $5 \mu \mathrm{g} / \mathrm{ml})$. Here, the result was found that $24 \mathrm{hrs}$ of immobilization time was the optimum time for the reagent immobilization in the film. This is because, at $24 \mathrm{hrs}$, the color change of the test when reacted toward dexamethasone solution was optimum, as no further drastic color intensity change after $24 \mathrm{hrs}$ has been found. While for the time response was found that 10 min was optimum to show color change to the blue color toward dexamethasone solution. Since the $\Delta$ mean blue was relatively constant after $10 \mathrm{~min}$. This response was faster compared to other methods ${ }^{11}$. Therefore, it was selected as the response time for further measurement.
The dipstick test response toward various concentrations of dexamethasone under the optimal experimental parameters is shown in Table 1. It was found to be linear in the range between $0.5-75 \mu \mathrm{g} / \mathrm{ml}$, with correlation coefficient (r) 0,9997 . The sensitivity of the dipstick test was obtained from the linear curve slope, and it was found to be $0.4111 \Delta$ mean blue $/(\mu \mathrm{g} / \mathrm{ml})$ dexamethasone $(\mathrm{n}=3)$. The limit detection was calculated from the three-time of the standard deviation of the response to the blank sample, and it was found to be $0.422 \mu \mathrm{g} / \mathrm{ml}$, with a limit of quantification was calculated to be $1,406 \mu \mathrm{g} / \mathrm{ml}$.

The recovery test of the dipstick test in 5 $\mu \mathrm{g} / \mathrm{ml}$ dexamethasone measurement was performed by spiked individually with 30,45 , and $60 \%$ of dexamethasone solution ${ }^{15}$ and the recovery was found in the range of $99.978-101.144 \%$, indicated that the dipstick test is accurate and show promising as an analytical tool for dexamethasone detection. While the reproducibility based on the six replicates 
detection in three days showed the relative standard deviation (RSD), less than $0.196 \%$ values for each day, showing that the dipstick test has excellent precision $^{16}$.

Table 1. The dipstick test results toward various concentration of dexamethasone.

\begin{tabular}{ccccc}
\hline $\begin{array}{c}\text { Conc. } \\
\boldsymbol{\mu g} / \mathbf{m l}\end{array}$ & dipstick & $\begin{array}{c}\text { Average } \\
\Delta \text { mean Blue }\end{array}$ & SD & RSD \\
\hline 0,5 & 30.160 & 0.001 & 1.766 \\
1 & 30.358 & 0.002 & 0.792 \\
3 & 31.184 & 0.002 & 0.299 \\
4 & 31.572 & 0.002 & 0.172 \\
5 & & 32.019 & 0.001 & 0.154 \\
16 & 36.508 & 0.003 & 0.035 \\
20 & & 38.035 & 0.006 & 1.148 \\
30 & & 42.268 & 0.001 & 1.084 \\
75 & & 60.620 & 0.005 & 1.092 \\
\hline
\end{tabular}

*triplicate measurements

The preliminary study on the selectivity of the dipstick test is performed using other potential adulterants that may be used in jamu, using $5 \mu \mathrm{g} / \mathrm{ml}$ dexamethasone solution in the presence of others. Here, other adulterants using non-corticosteroid, such as mefenamic acid, paracetamol, antalgin, and corticosteroid, such prednisone were tested. The concentration of each adulterant used was 1 , 10,100 , and $1000 \mu \mathrm{g} / \mathrm{ml}$ with the $1: 1$ volume ratio toward $5 \mu \mathrm{g} / \mathrm{ml}$ dexamethasone was used. The result was found for non-steroid adulterants, such as paracetamol and antalgin gave interference at the lowest concentration ratio of 1:200, while mefenamic acid did not give any interference toward the dipstick test response The other corticosteroid, such as prednisone exhibited interference at concentration ratio 1:20. These adulterants exhibited interference when the $\Delta$ mean blue as the response was higher than $5 \%{ }^{17}$. However, it would be difficult to use this method for the selective assay of several bulk corticosteroids simultaneously ${ }^{18}$. This test will also give a response to corticosteroids, such as prednisolone, prednisone, and hydrocortisone since they also show the blue color change. However, if no corticosteroids as adulterant present in the sample, the dipstick will not change the color.

The stability study of the dipstick test in two storage temperatures, such as room $\left(25^{\circ} \mathrm{C}\right)$ and chiller $\left(4^{\circ} \mathrm{C}\right)$ conditions, was conducted, its response towards dexamethasone $(5 \mu \mathrm{g} / \mathrm{ml})$ was observed every day, until more than $15 \%$ decrease from its initial response was found. Here, it was found that the response was decreased by more than $15 \%$ after 14 days at room temperature. While in the chiller, it was found that the response was shown to be preserved until 21 days.

The dexamethasone present in various jamu samples for the joint-paint killer has been detected using the dipstick test and the UV spectrophotometric method. In the case where UV 
spectrophotometric method ${ }^{13}$ was used as the reference method, the linear range was achieved at the range $0-75 \mu \mathrm{g} / \mathrm{ml}$. with a linear equation was $\mathrm{Abs}=$ $0.1116+0.0024$ [Dexamethasone], and correlation coefficient (r) 0.9999 . The limit detection was found to be $0.369 \mu \mathrm{g} / \mathrm{ml}$, with a limit of quantification was $1.233 \mu \mathrm{g} / \mathrm{ml}$. While reproducibility of dexamethasone analysis in plant-derived samples was $3.687 \%$ and recovery values were between $100.079-100.318 \%$. This can be stated that the UV spectrophotometric method can be used as a reference method in this case. The results showed by the dipstick test were similar to the result obtained by the spectrophoto- metry method (Table 2). Hence, It can be stated that the proposed method was in good correlation $(r=0.999)$ with the UV spectrophotometric method. The main advantage of the dipstick test as an analytical tool for the detection of the dexamethasone in jamu is a low-cost and rapid assay without losing sensitivity and accuracy. Furthermore, the dipstick test can be also used as a screening tool using a naked eye (Fig. 1(d)) that is suitable for field applications. Moreover, the use of very common chemicals like ferric chloride and sulphuric acid which can easily find in most laboratories makes this method very easy to be fabricated.

Table 2. The result for the detection of dexamethasone adulteration in Jamu using the dipstick test and UV Spectrophotometry.

\begin{tabular}{|c|c|c|c|c|}
\hline \multirow[t]{2}{*}{ Sample } & Dipstic & & UV-spectrophotometry** & \multirow{2}{*}{$\begin{array}{c}\text { ttest }_{\text {cal }} \\
\text { (t-test }_{\text {teo }}> \\
0.05)\end{array}$} \\
\hline & \multicolumn{3}{|c|}{ Dexamethasone detected $(\mu \mathrm{g} / \mathrm{ml})$} & \\
\hline $\mathrm{A}$ & 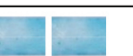 & $4.788 \pm 0.001$ & $4.690 \pm 0.052$ & \multirow{5}{*}{0.975} \\
\hline $\mathrm{B}$ & & $2.624 \pm 0.001$ & $2.631 \pm 0.058$ & \\
\hline $\mathrm{C}$ & & $6.250 \pm 0.001$ & $6.540 \pm 0.104$ & \\
\hline $\mathrm{D}$ & & $3.088 \pm 0.001$ & $3.090 \pm 0.052$ & \\
\hline $\mathrm{E}$ & & $0.190 \pm 0.003$ & $0.167 \pm 0.012$ & \\
\hline
\end{tabular}

*Five replications; **triplicate

\section{CONCLUSIONS}

The dipstick test based on immobilized $\mathrm{FeCl}_{3}$ and $\mathrm{K}_{3}\left[\mathrm{Fe}(\mathrm{CN})_{6}\right]$ onto cellulose acetate film was developed using colorimetric detection coupled with the scanometric method for dexamethasone detection in jamu samples. The response time was found in 10 mins that is faster than the UV spectrophotometric method, while dexamethasone concentration in jamu samples determined by both methods was in good agreement. Here, the reagent and sample solution used in the dipstick test for dexamethasone detection in jamu, was drastically reduced, including the operating cost for performing the analysis. Thus, the dipstick test can be used as an alternative tool for the detection of dexamethasone adulteration in traditional herbal medicine (jamu) using scanometric method or as a screening tool using a naked eye.

\section{ACKNOWLEDGMENTS}

This work was supported by LP2M,
University of Jember, Indonesia via Keris Research Grant [No. 6707/UN25/LT/2019].

\section{Conflict of interest}

No conflict of interest in this work

\section{Funding}

None to declare

\section{Ethical approval}

Must be declare

\section{Article info:}

Received July 19, 2019

Received in revised form May 4, 2020

Accepted May 19, 2020

\section{REFERENCES}

1. Elfahmi, Woerdenbag HJ, Kayse O. Jamu: Indonesian traditional herbal medicine towards rational phytopharmacological use. J Herb Med.2014;4:51-73. 
2. Beers SJ. Jamu: the ancient Indonesian art of herbal healing. Hong Kong: Turtle Publishing; 2001. $192 \mathrm{p}$.

3. Garvey GJ, Hahn G, Lee RV, Harbison RD. Heavy metal hazards of Asian traditional remedies. Int J Environ Health Res.2001;11: 63-71.

4. Mukherjee PK, Houghton PJ. Evaluation of herbal medicinal products : perspective on quality, safety and efficacy. Pharmaceutical Press; 2009. 520 p.

5. Mustarichie R, Ramdhani D, Indriyati W. Analysis of forbidden pharmaceutical compounds in antirheumatic jamu. Asian J Pharm Clin Res. 2017;10:98-101.

6. Ofori-Kwakye K, Ayensu I, Akyinah B, Kipo S, Boakye-Gyasi M. Adulteration of Ghanaian topical herbal preparations with dexamethasone. World J Pharm Pharm Sci. 2014;3:134-41.

7. Lemus Gallego J, Pérez Arroyo J. Spectrophotometric resolution of ternary mixtures of dexamethasone, polymyxin $b$ and trimethoprim in synthetic and pharmaceutical formulations. Anal Chim Acta. 2001;437:247-57.

8. Jin P, Liang X, Wu X, He X, Kuang Y, Hu X. Screening and quantification of 18 glucocorticoid adulterants from herbal pharmaceuticals and health foods by HPLC and confirmed by LC-Q-TOF-MS/MS. Food Addit Contam Part A. 2018;35:10-19.

9. Zhou S, Guo C, Shi F, Jiang W, Wang L. Application of an ultrahigh-performance liquid chromatography coupled to quadrupoleorbitrap high-resolution mass spectrometry for the rapid screening, identification and quantification of illegal adulterated glucocorticoids in herbal medicines. J Chromatogr B
Analyt Technol Biomed Life Sci. 2016;1038: 34-42.

10. Cho SH, Park HJ, Lee JH, Kim HJ, Cho S, Yoon CY, et al. Monitoring of 35 illegally added steroid compounds in foods and dietary supplements. Food Addit Contam Part A. 2014;31: 1470-5.

11. Singh DK, Verma R. Spectrophotometric determination of corticosteroids and its application in pharmaceutical formulation. Oxid Commun. 2009;32:678-84.

12. Ensafi AA, Fouladgar M. Development of a mercury optical sensor based on immobilization of 4-(2-pyridylazo)-resorcinol on a triacetylcellulose membrane. Sensors Actuators B Chem. 2006;113:88-93.

13. Friedrich RB, Ravanello A, Cichota LC, Rolim CMB, Beck RCR. Validation of a simple and rapid UV spectrophotometric method for dexamethasone assay in tablets. Quim Nova. 2009;32:1052-4.

14. Miller J, Miller J. Statistics and Chemometrics for Analytical Chemistry. $6^{\text {th }}$ ed. Pearson Education; 2010. 278 p.

15. Huber L. Validation and Qualification in Analytical Laboratories. $2^{\text {nd }}$ ed. Informa Healthcare; 2007. 288 p.

16. Yuwono M, Indrayanto G. Validation of chromatographic methods of analysis. Profiles Drug Subst Excipients Relat Methodol. 2005; 32:243-59.

17. Thompson M, Ellison SLR. A review of interference effects and their correction in chemical analysis with special reference to uncertainty. Accredit Qual Assur. 2005;10:82-97.

18. Council of Europe. European Pharmacopoeia 6.0. 2008 . 